\title{
Identification and Mapping of Essential Fish Habitats Using Remote Sensing and GIS on Lake Victoria, Kenya
}

\author{
Mark Kipkurwa Boitt ${ }^{1 *}$, Erick Otieno Aete $^{2}$ \\ ${ }^{1}$ Institute of Geomatics, GIS and Remote Sensing (IGGReS), Dedan Kimathi University of Technology, Nyeri, Kenya \\ ${ }^{2}$ Department of Geomatic Engineering and GIS (GEGIS), Jomo Kenyatta University of Agriculture and Technology, \\ Nairobi, Kenya \\ Email: *mark.boitt@dkut.ac.ke
}

How to cite this paper: Boitt, M. K., \& Aete, E. O. (2021). Identification and Mapping of Essential Fish Habitats Using Remote Sensing and GIS on Lake Victoria, Kenya. Journal of Geoscience and Environment Protection, 9, 91-109.

https://doi.org/10.4236/gep.2021.910007

Received: June 15, 2021

Accepted: October 22, 2021

Published: October 25, 2021

Copyright $\odot 2021$ by author(s) and Scientific Research Publishing Inc. This work is licensed under the Creative Commons Attribution International License (CC BY 4.0).

http://creativecommons.org/licenses/by/4.0/

\begin{abstract}
Fisheries in Lake Victoria have been threatened by declining fish stocks and diversity, environmental degradation due to increased input of pollutants, industrial and municipal waste, overfishing and use of unapproved fishing methods, infestation by aquatic weeds especially water hyacinth, de-oxygenation and a reduction in the quantity and quality of water. Remote sensing and GIS are essential tools in detection of fishing grounds which is important in providing fish sustainability for human beings and allows fishing grounds detection at minimal cost and optimizes effort. This research tends to identify the most favorable both environmentally and ecologically satisfactory factors which favor fish breeding and growth. The main aim of the study was to identify habitat variables that promote fish breeding and growth to maturity including the extraction of environmental variables from Landsat 8 images for the study period and using suitability index derived from fishery data. The study concentrated on establishing suitability ratings in different parts of Lake Victoria using lake surface temperature and chlorophyll-a levels. The study was conducted for months; January, May and December 2019 on Lake Victoria (limited by the availability of recent data). The factors were analysed and the favorable regions mapped satisfying the conditions for fish breeding. The output obtained illustrated the availability of suitable and habitable zones within the lake using satellite imagery and the suitability index. The fish catch data and satellite derived variables were used to determine habitat suitability indices for fish during January, May and December 2019. More than $90 \%$ of the total catch was found to come from the areas with sea surface temperature of $23.0^{\circ} \mathrm{C}-28.3^{\circ} \mathrm{C}$ and chlorophyll-a concentration between $0.72-1.31$ $\mathrm{mg} / \mathrm{m}^{3}$. The catch data was used to validate the images. This study indicated
\end{abstract}


the capability of High Satellite Resolution Imageries (HSI) as a tool to map the potential fishing grounds of fish species in Lake Victoria. The variables were affected by climatic change factors like rainfall and temperature of the lake basin and other human activities around the lake and also the species ecosystem like competition or predation.

\section{Keywords}

Catch Per Unit Effort, Potential Fishing Zones, Geographic Information Systems, High Resolution Satellite Image, Habitat Suitability Index

\section{Introduction}

\subsection{Background}

Lake Victoria supports the largest inland freshwater fishery on earth. The Kenyan portion of the lake covers an area of $4128 \mathrm{~km}^{2}$ and produces the bulk (80\%) of the country's annual fish landings. The lake had high fish species diversity of over 500 species of fish most of which were endemic but following the introduction of Nile perch and tilapiine cichlids, coupled with over exploitation and environmental degradation, many native species have since disappeared from the lake. The main commercial species caught are Rastreonobola agentea (Omena/dagaa/mukene) $53.32 \%$, Lates niloticus (Nile Perch) $33.4 \%$ and Oreochromis niloticus (Tilapia) $4.31 \%$. Fish stocks have dwindled due to heavy eutrophication, proliferation of invasive species, over-fishing and use of illegal/undersize gears.

Ecological processes at various temporal and spatial scales have created a vast array of distribution patterns (Nyamweya et al., 2016). The configuration of habitats and the distribution of species along environmental gradients have for a long time also been affected by human interests and development. For example, in 1877, applied ecology sought the answer to an unexpected low production of an oyster bank in response to fisheries management needs. Today, as habitat loss poses a major threat to ecosystems (Aryaguna, 2019), the need to map species and habitat distributions for nature conservation has increased dramatically (Vayghan et al., 2013). Ecologists' interests in understanding population distribution and dynamics, combined with advancements in computer technology, have led to the development of species distribution modelling. This field of spatial modelling relates the occurrence or abundance of species to environmental descriptors and can help resolve, or raise, ecological and evolutionary questions into the underlying processes and mechanisms regulating species and habitat distributions.

\subsection{Objectives}

The objectives of this study were to:

1) To identify the habitat variables that promote fish breeding. 
2) To extract lake surface temperature and chlorophyll-a from satellite imagery.

3) Determine potential fishing grounds using Habitat Suitability Index (SI).

\section{Materials and Methods}

\subsection{Study Area}

Lake Victoria traverses the three East African Countries: Kenya, Uganda and Tanzania. It lies within longitudes $33^{\circ} 52^{\prime} 55^{\prime \prime}$ and $35^{\circ} 00^{\prime} 45^{\prime \prime}$ East and latitudes $0^{\circ} 22^{\prime} 42^{\prime \prime}$ North and $1^{\circ} 00^{\prime} 34^{\prime \prime}$ South. It has a surface area of $68,500 \mathrm{~km}^{2}$ shared between Kenya (6\%), Uganda (43\%) and Tanzania (51\%). The Kenyan portion of the lake covers an area of $4128 \mathrm{~km}^{2}$.

The climate in the lake basin varies from tropical rain forest with rainfall over the lake for much of the year to a semi dry climate with intermittent droughts over some areas. Figure 1 shows the study area.

\subsection{Data}

Landsat images for the months January, May and December, 2019 were acquired from USGS website were used. Fishery data was acquired from Kenya Marine and Fisheries Research Institute (KMFRI) where different fishing methods was represented in the data. The fishery data together with the suitability index was used to validate the remote sensing images. Table 1 gives an indication of the data used in this research.

\subsection{Methods}

For this research, the satellite images were imported, reprojected to change the

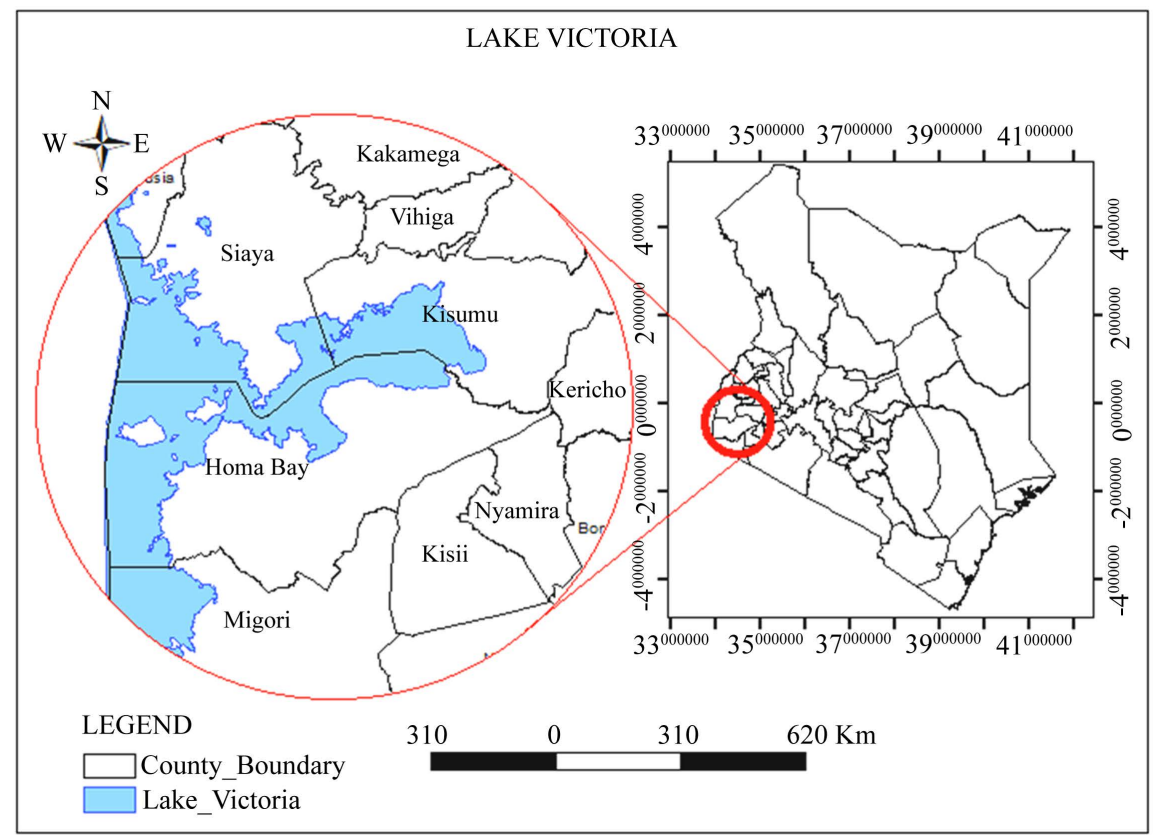

Figure 1. Study area. 
Table 1. Data sets.

\begin{tabular}{cccccc}
\hline Data type & Sensor & Band & Wavelength & Rsln & Use \\
\hline Satellite image & Landsat 8 & Band 2 & $0.45-0.51$ & 30 & Chl-a extraction \\
& & Band 3 & $0.53-0.59$ & 30 & Chl-a extraction \\
& & Band 4 & $0.64-0.67$ & 30 & Chl-a extraction \\
& Band 5 & $0.85-0.88$ & 30 & Chl-a extraction \\
& & Band 10 & $10.6-11.19$ & 100 & L.S.T extraction \\
& & Band 11 & $11.5-12.51$ & 100 & L.S.T extraction \\
Fishery data & - & - & - & - & PFZ map \\
\hline
\end{tabular}

projection to UTM. Subset was extracted to obtain area of interest or region of interest (subset image). Image correction such as radiometric calibration, atmospheric correction for cloud filtering, then lake surface temperature and chlorophyll-a were extracted from the image (see Figure 2).

The estimated data was obtained by the Landsat 8 Thermal Infrared Sensor (TIRS). Landsat 8 provides metadata of the bands such as thermal constant, rescaling factor value (Figure 3 ).

First, the digital number (DN) of band 10 and band 11 had to be converted to radiance by using following Formula (1);

$$
L_{\lambda}=M_{\lambda} \times Q_{\text {cal }}+A_{\lambda}
$$

where:

$L_{\lambda}$ is the top of the atmosphere spectral radiance,

$M_{\lambda}$ is band specific multiplicative rescaling factor,

$Q_{c a l}$ is digital number,

$A_{\lambda}$ is the band specific additive rescaling factor.

Then, converted them to the brightness temperature by using this Formula (2);

$$
T=\frac{K_{2}}{\ln \left(\frac{K_{1}}{L_{\lambda}}+1\right)}
$$

where $T$ is at satellite brightness temperature (Kelvin), $K_{1}$ and $K_{2}$ are thermal conversion constants from metadata.

Calculation of NDVI was important because subsequently the proportion vegetation (PV), which is highly related to NDVI and emissivity $(e)$ which is related to PV must be calculated using Formula (3).

$$
\text { NDVI }=\frac{\text { Band } 5-\text { Band } 4}{\text { Band } 5+\text { Band } 4}
$$

Proportion of vegetation was computed to estimate the emissivity. Usually, the maximum and the minimum values of NDVI image are displayed directly in the image in ArcGIS, therefore PV is calculated as follows in Formula (4); 


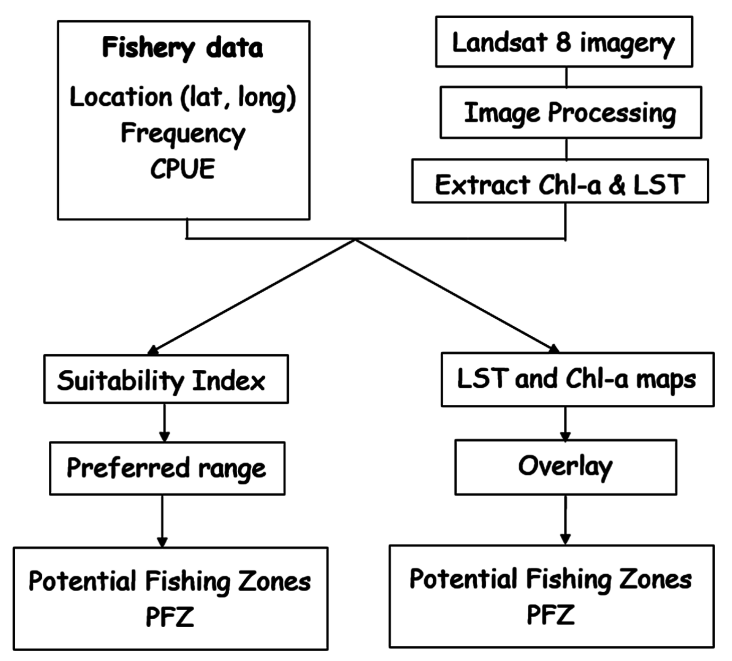

Figure 2. The workflow.

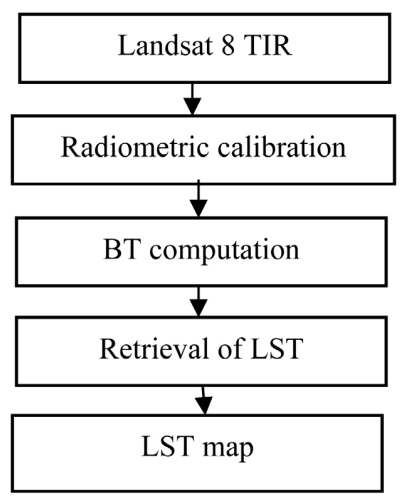

Figure 3. Land surface estimation.

$$
\mathrm{PV}=\left(\frac{\mathrm{NDVI}^{-} \mathrm{NDVI}_{\text {min }}}{\mathrm{NDVI}_{\max }-\mathrm{NDVI}_{\text {min }}}\right)^{2}
$$

Emissivity was computed as follows using Formula (5):

$$
e=0.004 * \mathrm{PV}+0.986
$$

in the raster calculator.

The value 0.986 correspond to correction value of the equation and 0.004 is a constant as illustrated by USGS website.

Finally, the LST equation was applied to obtain the surface temperature map using Formula (6).

$$
\mathrm{LST}=\frac{\mathrm{BT}}{1+(\lambda * \mathrm{BT} / \mathrm{C} 2) * \ln (e)}
$$

$$
\mathrm{C} 2=14,388 \mu \mathrm{m}
$$

The values of $\lambda$ for Landsat bands include.

Chlorophyll-a was extracted as follows, since the Landsat-8 data (Table 2) was stored in digital number $(D N)$. It had to be radiometrically converted to the top-of-atmosphere radiance $\left(L_{T O A}\right)$ by using following Formula (7); 
Table 2. Bands spectral radiance for Chlorophyll-a.

\begin{tabular}{ccc}
\hline Satellite & Band & $\lambda(\mu \mathrm{m})$ \\
\hline Landsat $4,5 \& 7$ & 6 & 11.45 \\
Landsat 8 & 10 & 10.8 \\
Landsat 8 & 11 & 12 \\
\hline
\end{tabular}

$$
L_{\lambda}=M_{\lambda} \times Q_{c a l}+A_{\lambda}
$$

where:

$L_{\lambda}=$ TOA spectral radiance

$M_{\lambda}=$ Band specific multiplicative rescaling factor

$Q_{\text {cal }}=$ Digital Number

$A_{\lambda}=$ Band specific additive rescaling factor

After obtaining the radiance value, the next step was atmospheric correction that will automatically convert the top-of-atmosphere radiance value $\left(L_{T O A}\right)$ to bottom of atmosphere reflectance using FLAASH in ENVI 5.3. FLAASH incorporates the MODTRAN radiation transfer code. It enables corrections for the adjacency effect or pixel mixing due to scattering of surface-reflected radiance.

The chlorophyll-a was extracted using band 2 and band 4 in Landsat image as follows (Formula (8));

$$
\text { Chl_a = Band 4/Band } 2
$$

The above processes were repeated for all the images (January, May and December 2019).

Fish catch frequency were analyzed to determine the preferred range of the fish by relating the availability of fish catch data with the satellite images (Wanchana \& Sayan, 2018). Fishing effort is often considered to be an index of fish availability or fishing occurrence. This is to derive suitability index. Habitat suitability index (HSI) models are widely used as a tool in fisheries management, ecological impact assessments and ecological restoration studies (Tidd et al., 2018). The HSI models usually describe relations between fish abundance and ecological variables and estimate the level of habitat suitability. HSI objectively assess the range of environmental condition that fully, marginally or do not meet the requirements of a species. Output produced from HSI modeling can predict the spatio-temporal variation of fish habitat conditions and can be used in combination with GIS to provide maps and information upon which managers can make informed decisions in fisheries management (Mustapha et al., 2010).

Suitability Index Formula (9);

$$
\mathrm{SI}=\frac{Y_{f i t}-\min Y_{f i t}}{\max Y_{f i t}-\min Y_{f i t}}
$$

where $Y_{\text {fit }}$ is the predicted value of frequency $(C P U E) ; \min Y_{\text {fit }}$ and $\max Y_{\text {fit }}$ are, respectively, the minimum and maximum frequency (CPUE). The suitability index determined the level of scores of the preferred ranges for fish. The satel- 
lite images were reclassified using these relevant scores to derive map of potential fishing area.

\section{Results and Discussion}

\subsection{Lake Surface Temperature}

The lake surface temperature was obtained for the months January, May and December. The red regions represented high temperature areas and green represents low temperature areas. For January the high temperature was observed along the lake shores of Kisumu, and parts of Siaya and Busia counties. Optimum temperature for fish breeding were along Homa bay county and some along Siaya counties (Figure 4). Trisakti et al. (2004) analysed sea surface temperature using Landsate 7 ETM to understand potential fishin zones. Syariz et al. (2015) also did the same process for ecological studies.

In May high temperature was along Kisumu and Homabay while other counties the temperature were varying and cooler were in the interior of the lake (Figure 5).

December recorded higher temperatures along Kisumu and Busia counties and lower along other counties and parts of Mbita where the temperature was optimum (Figure 6).

\subsection{Chlorophyll-a}

High chlorophyll-a concentration areas i.e., along shores of Kisumu, Homa bay along Rangwe, Mbita, Karachuonyo and some parts along Siaya county. This is an indication of thriving phytoplankton which fish feed on. The dark blue regions are those which show high chlorophyll-a concentration while the reddish regions show low concentration. The optimum chlorophyll-a concentration was observed in the Homa bay and Siaya county beaches. This was constantly observed throughout the three months; January, May and December 2019 (Figure $7(\mathrm{a})-(\mathrm{c})$ ). Such reports have been dervived by Apriliani et al. (2018) in their studies. Similar studies were done by Lailia et al. (2015).

\subsection{Potential Fishing Zones}

\subsubsection{From the Overlay of the Chl-a Ans LST Maps}

The potential fishing zone (PFZ) map shows the areas which have the most conducive variables concentration and supports fish breeding and spawning. The blue regions are the most habitable regions which satisfy both temperature concentration and chlorophyll-a concentration. Highly habitable regions were observed around Mbita and other regions in Homa bay, Siaya, along the shores of Kisumu, Busia and Migori. The seasonal variation was influenced by the precipitation as well as temperature variation at different times of the year (see Figure $8(\mathrm{a})-(\mathrm{c})$ ). Such results have been developed by other authors (Dan Teknik et al., 2015; Mustapha et al., 2010; Syariz et al., 2015; Nurdin et al., 2012) which showed similar approached to mapping potential fishing zones using remote sensing data. 


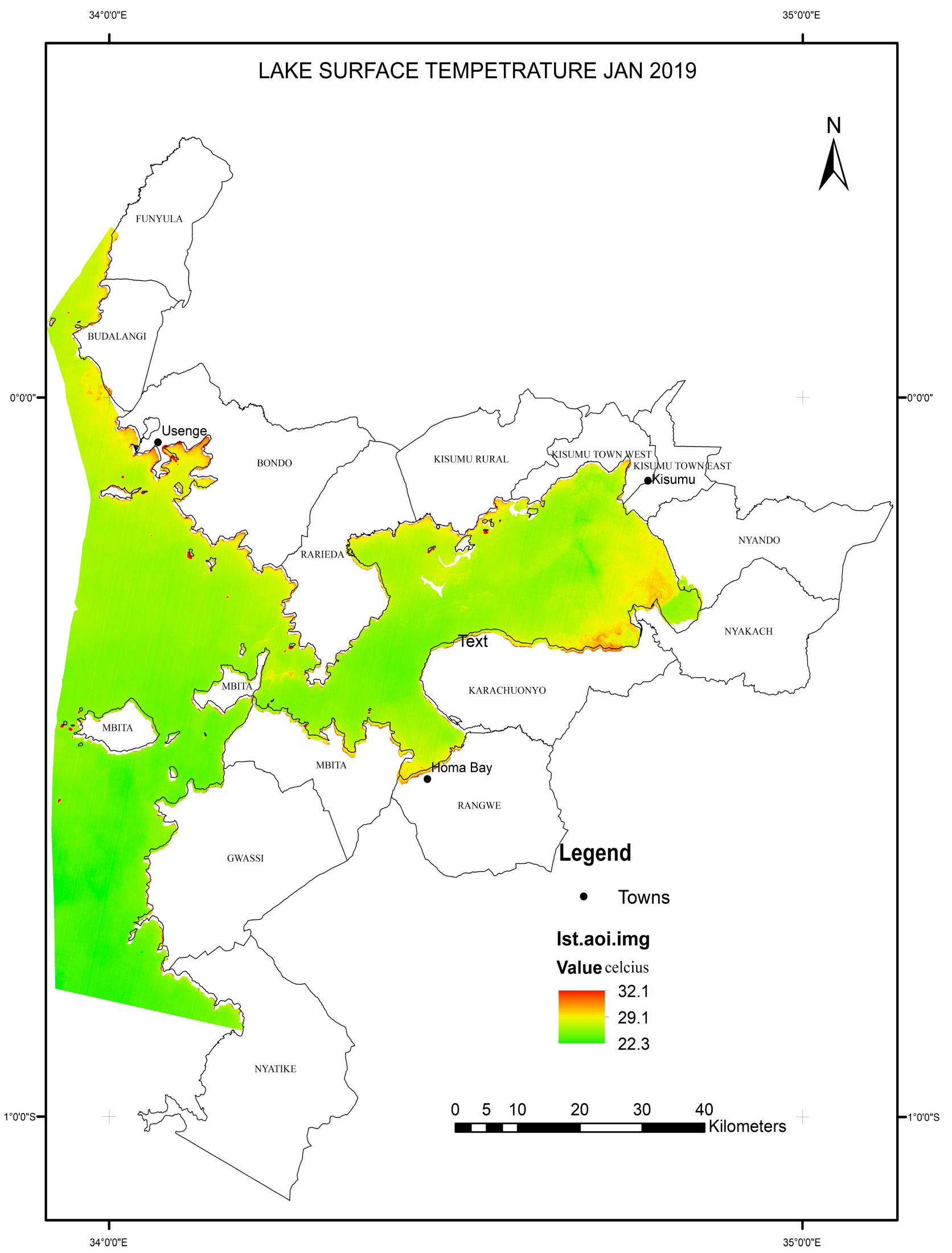

Figure 4. LST for January 2019. 


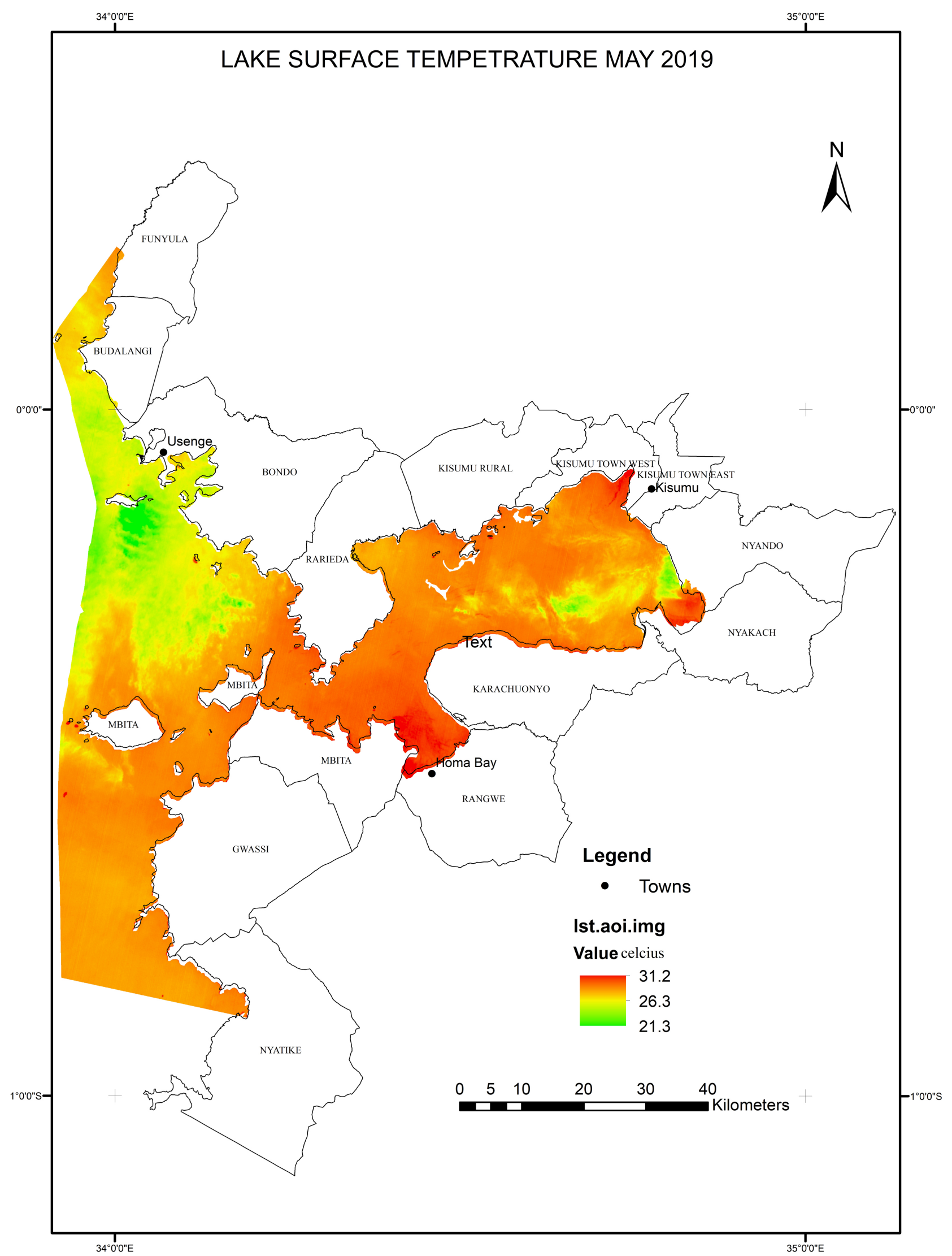

Figure 5. LST for May 2019. 


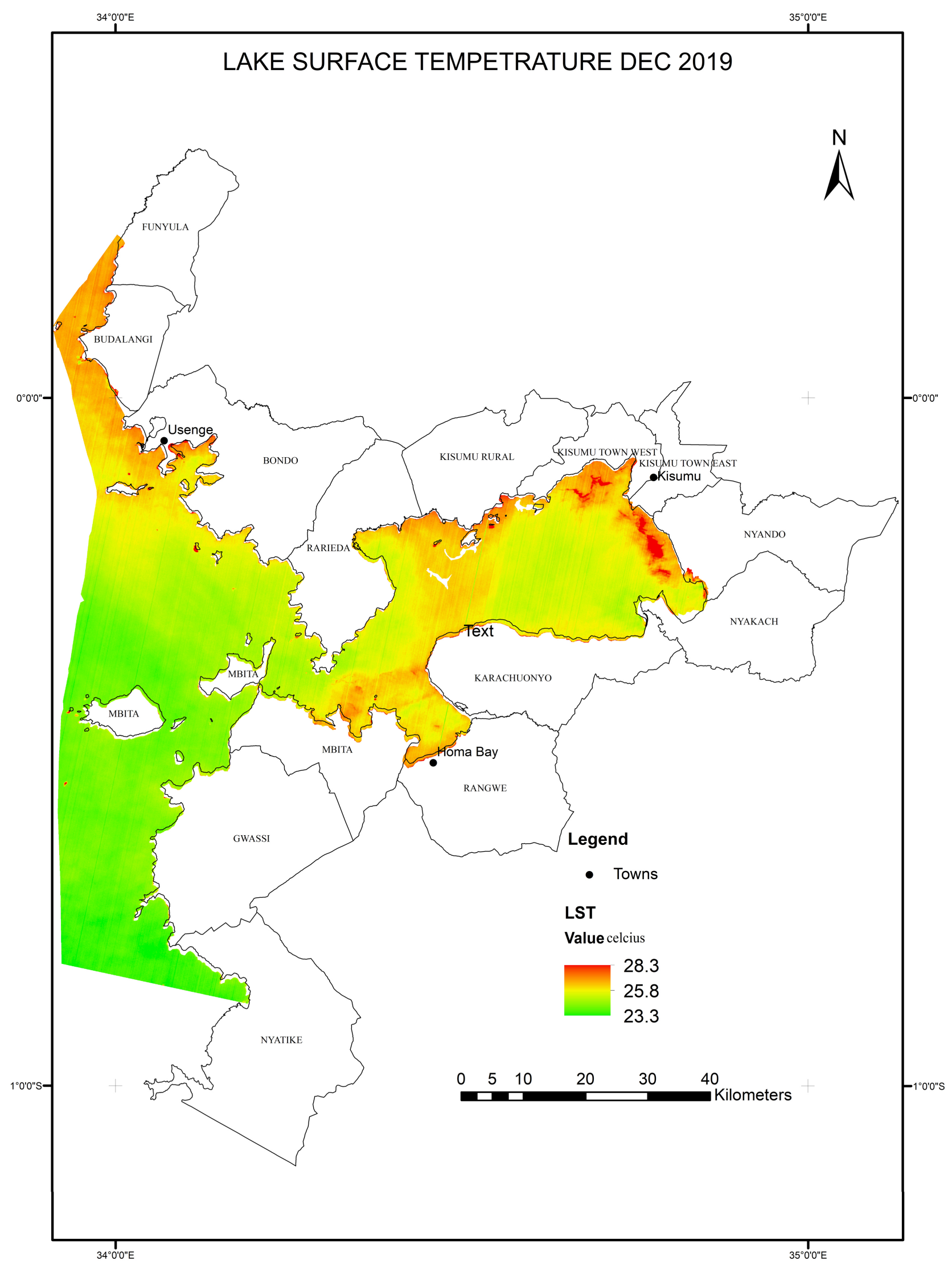

Figure 6. LST for December 2019. 


\section{CHLOROPHYL-A MAP JAN 2019}

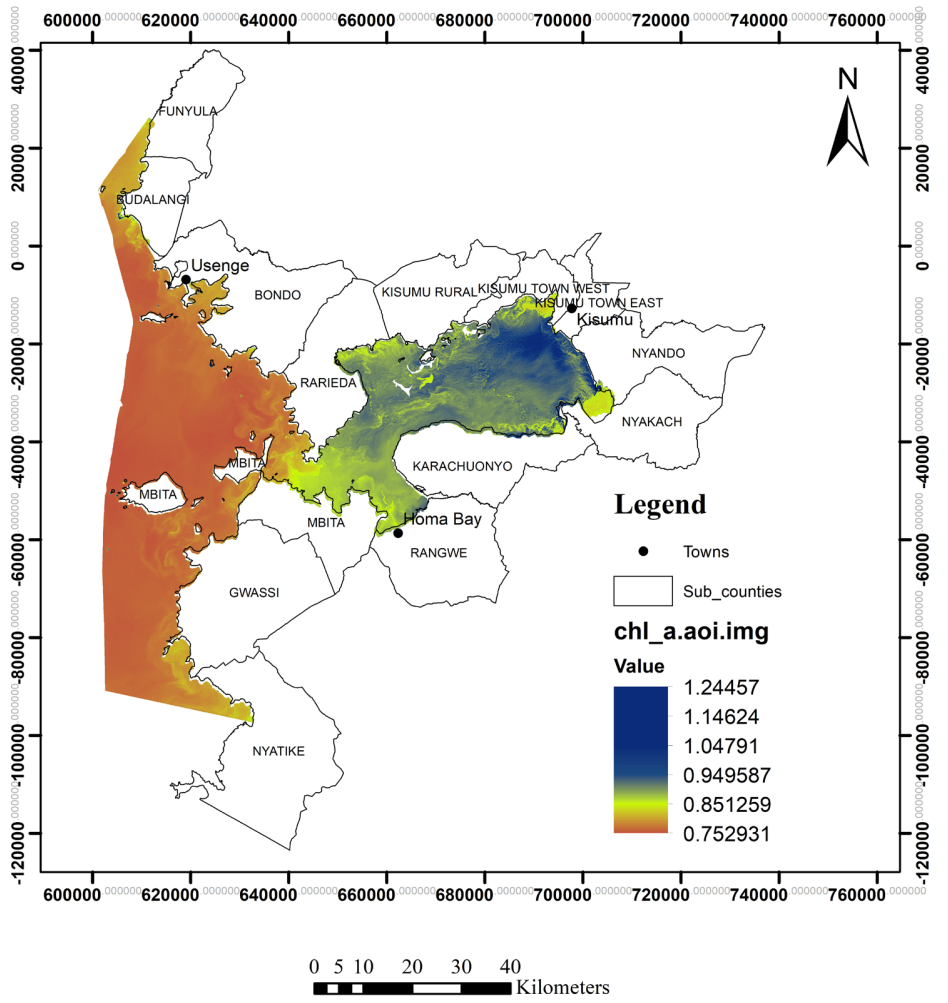

(a)

\section{CHLOROPHYL-A MAP MAY 2019}

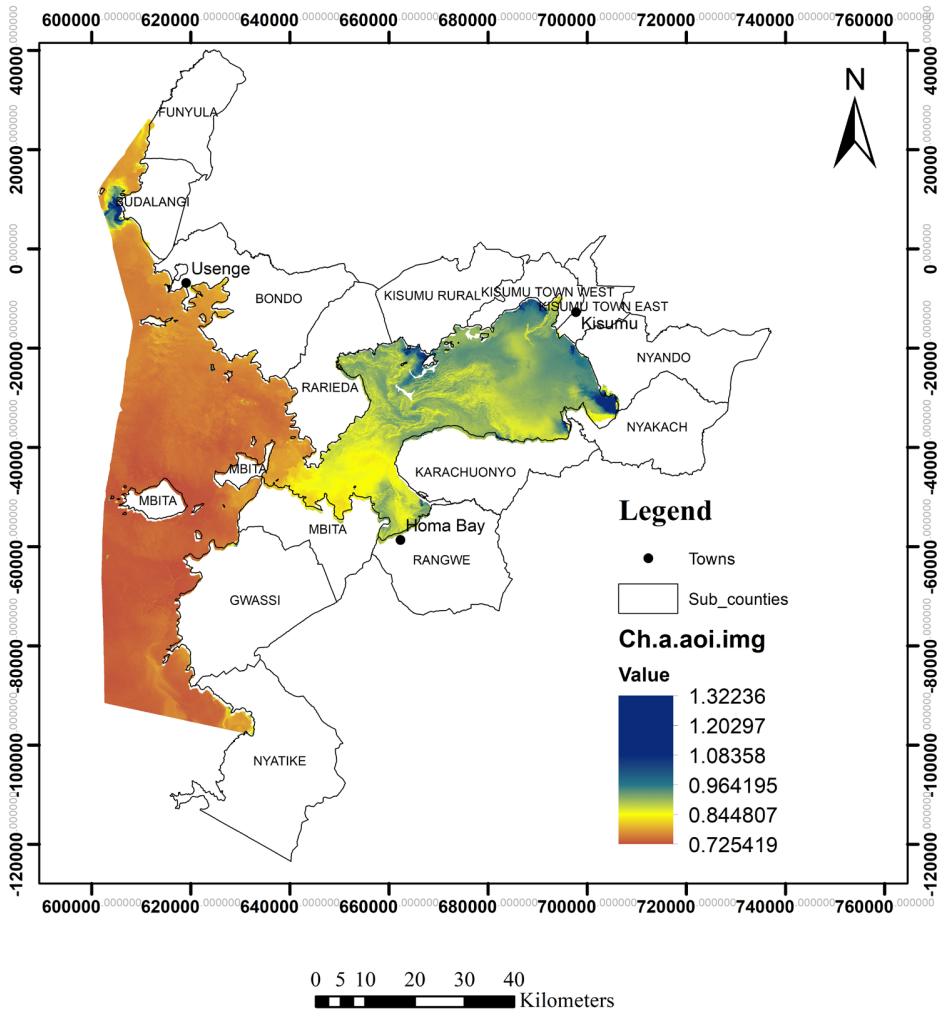

(b) 


\section{CHLOROPHYL-A MAP DEC 2019}

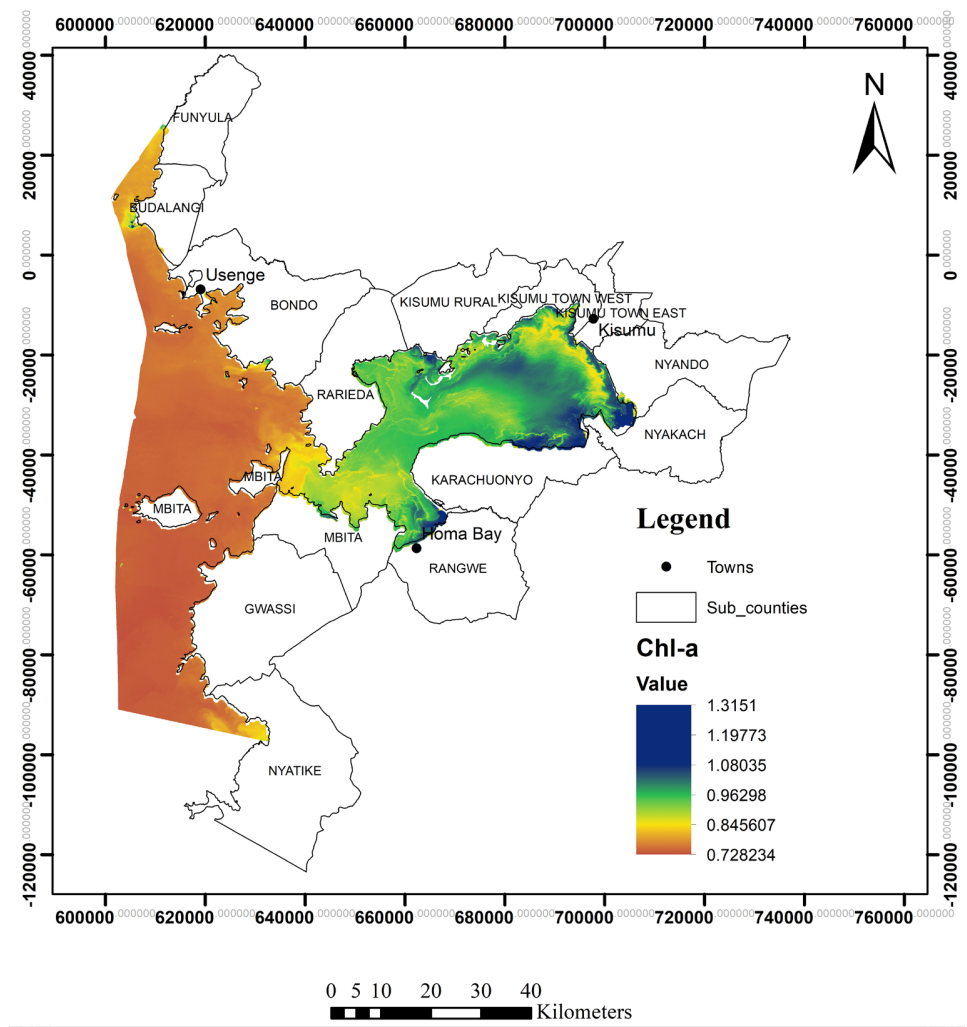

(b)

Figure 7. (a) Chl-a concentration for January, (b) May and (c) December 2019 respectively.

\subsubsection{Analysis of Suitability Index}

The actual fish catch was plotted on the map to indicate the actual fish catch value in the potential fishing zones. High potential fishing zones were obtained along the shores also the Homa bay county regions, parts of Siaya, Kisumu and Migori counties. Suitability Index analysis of preferred ranges for lake surface temperature and chlorophyll-a were as shown in Figure 9 below.

The suitability index was higher at optimum temperature an indication the most catch was obtained at optimum temperature regions i.e., from $24^{\circ} \mathrm{C}$ to $27^{\circ} \mathrm{C}$. High suitability index satisfies the optimum temperature which favors thriving of fish habitat variables thus abundance of fish (Figure 10).

The suitability index was higher at the optimum chlorophyll concentration ( 0.8 to $1.1 \mathrm{mg} / \mathrm{m}^{3}$ ) which favors the growth of phytoplankton which fish feed on.

\subsection{Seasonal Distribution of the Habitat}

From this study the distributions of the essential fish habitats were observed along beaches of Homa bay, Mbita region, this is due to abundance of chlorophyll-a in these regions as observed above. From Figure 11 below the distribution is represented in terms of the suitability index obtained from the CPUE. The low habitable regions are regions which registered catch of less than 10 


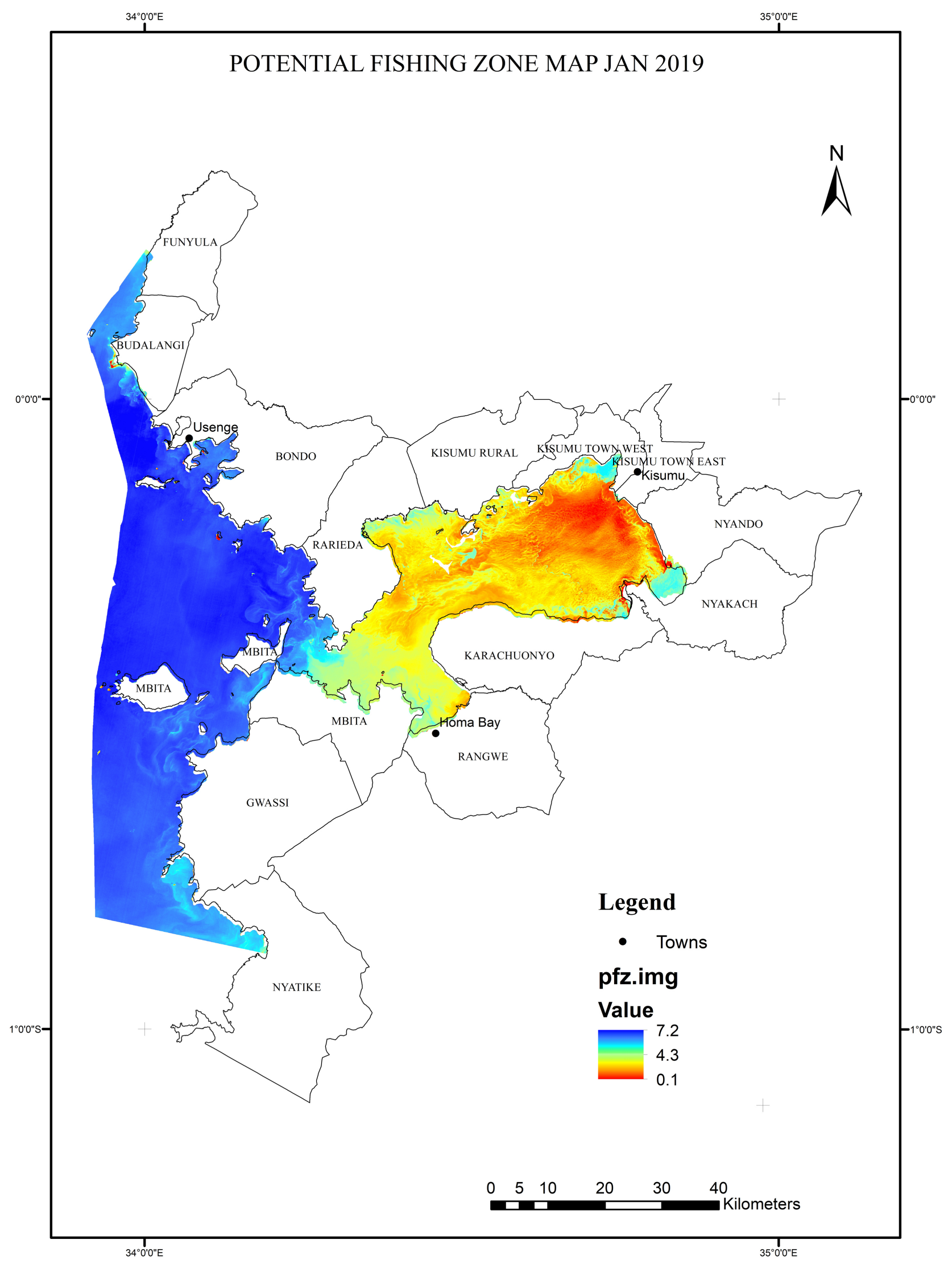

(a) 


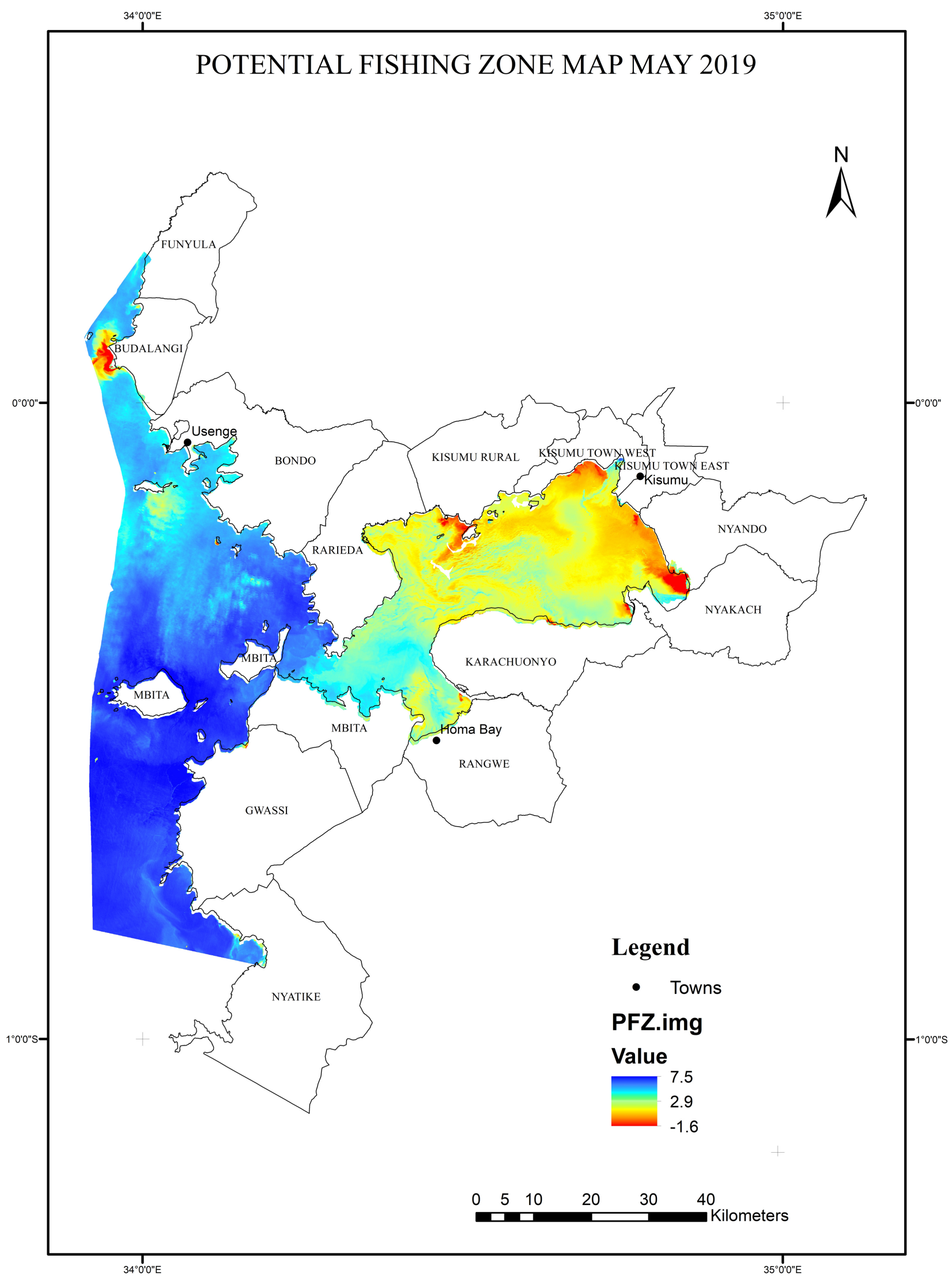

(b) 


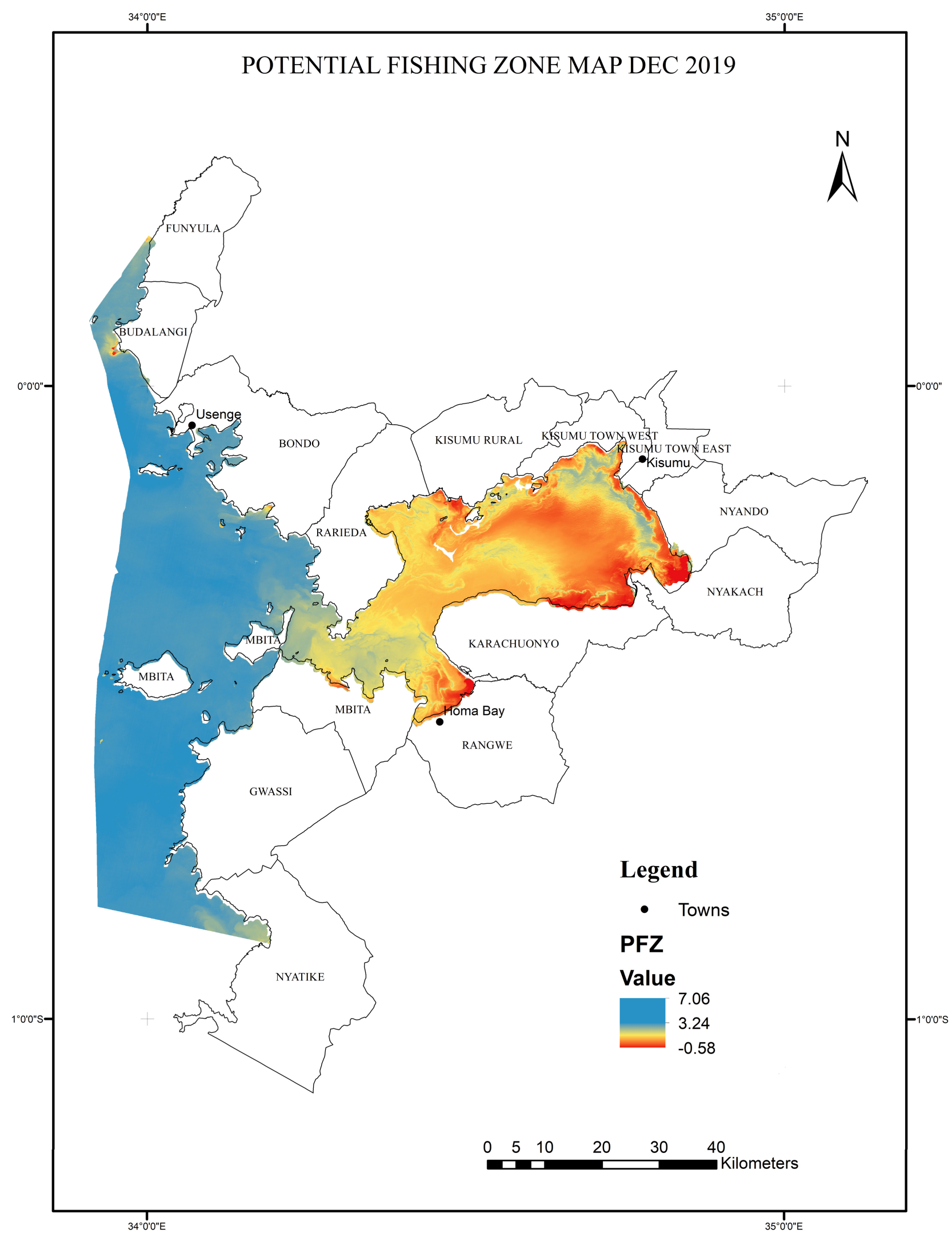

(c)

Figure 8. (a) Potential fishing zone map for Jan 2019, (b) May 2019 and (c) December 2019. 


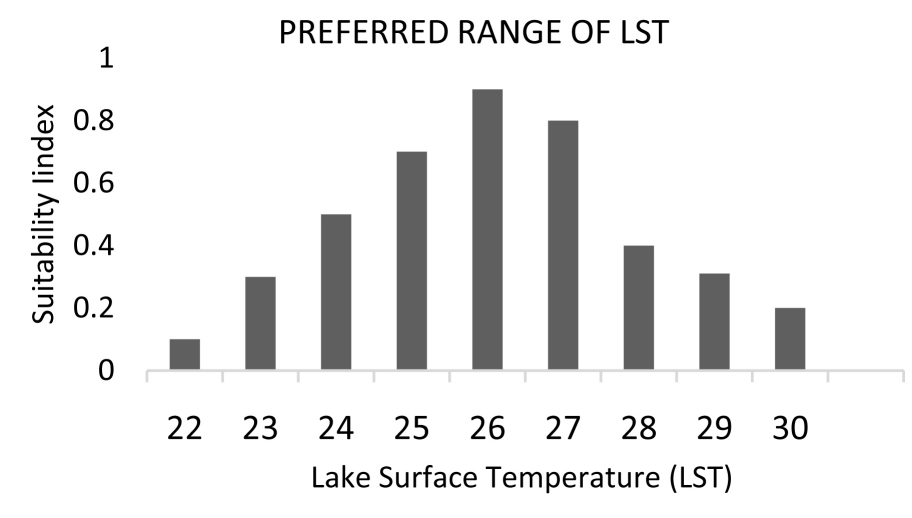

Figure 9. Suitability index analysis indicating preferred range of LST.

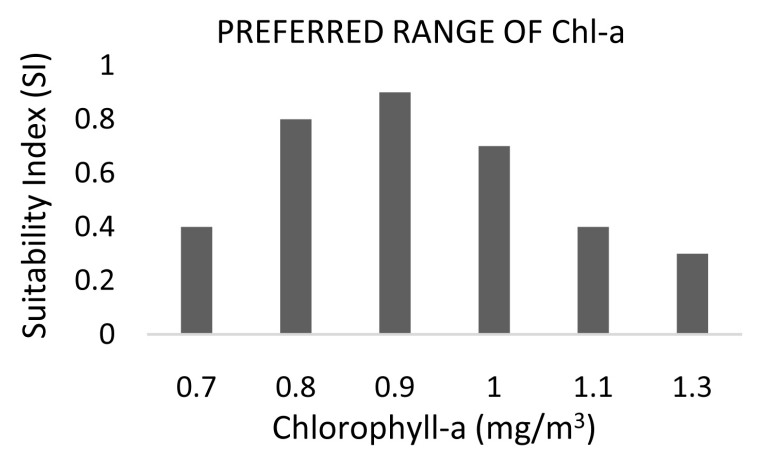

Figure 10. Suitability index analysis indicating preferred range of Chl-a.

metric tonnes, and were observed around Kisumu County. Highly habitable regions were observed along the Mbita in Homa bay county and some in Siaya county, they registered catch greater than 30 metric tonnes. Other regions recorded between 10 and 30 metric tonnes as observed from the fishery data.

\section{Conclusion}

In this study, the data used were caught data and satellite derived environmental variables to determine habitat suitability indices for fish. We found that more than $90 \%$ of the total catch came from the areas with sea surface temperature $23.0^{\circ} \mathrm{C}-28.3^{\circ} \mathrm{C}$ and chlorophyll-a concentration $0.72-1.31 \mathrm{mg} / \mathrm{m}^{3}$. This study demonstrated that potential fishing zones of fish can be mapped using suitability index model, with fish catch data and satellite imagery components. The satellite data is advantageous since they categorize the aquatic properties of habitat and ecosystems that influence living aquatic resources at spatial and temporal resolutions. Based on the datasets available, there is a variation in the level of nutrients, chlorophyll-a and lake surface temperature in Lake Victoria. The lake can be classified as a shallow nutrients-rich productive area between shore and offshore and are important in sustaining the fishery ecosystem in the lake.

The study can therefore be concluded that the most essential fish habitat regions in the Lake Victoria were along Homa bay and Siaya regions as observed from Figure 8 and Figure 11. Fish habitat is dynamic and changes due to 


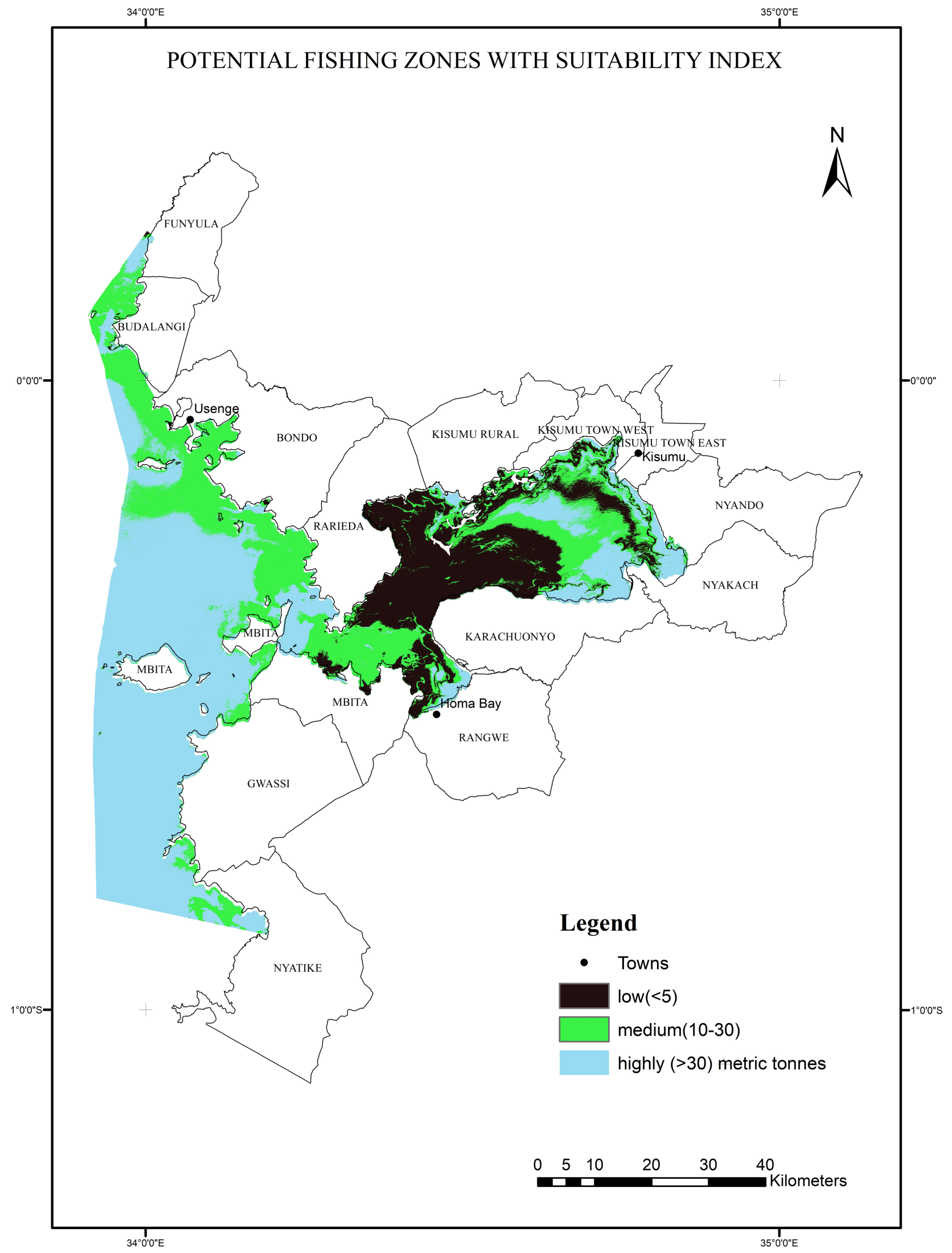

Figure 11. Potential fishing zone map using suitability index. 
environmental, climatic factors and also human activities affecting the lake and its surrounding. The PFZ maps varied for the months indicating that the habitat is not constant since the factors vary with precipitation for instance affects the chlorophyll concentration for phytoplanktons thriving. Therefore, Habitat Suitability Index is an essential tool for mapping essential fish habitats.

\section{Acknowledgements}

We would like to thank the providers of the data (NASA USGS and KMFRI) and all that supported this project in providing relevant information for use during the analysis stages.

Our sincere appreciation goes to our university departments: (IGGReS) and to GEGIS department in particular for providing a conducive environment, support and equipment during this research period and mostly throughout the study. I also thank the Almighty for the good health.

\section{Conflicts of Interest}

The authors declare no conflicts of interest regarding the publication of this paper.

\section{References}

Apriliani, I. M., Nurrahman, Y. A., Dewanti, L. P., \& Herawati, H. (2018). Determination of Potential Fishing Ground for Hairtail (Trichiurus sp.) Fishing Based on Chlorophyll-A Distribution and Sea Surface Temperature in Pangandaran Waters, West Java, Indonesia. Aquaculture, Aquarium, Conservation \& Legislation, 11, 1047-1054.

Aryaguna, P. A. (2019). Habitat Suitability Mapping of Rastrelliger Brachysoma Using MODIS Image in WPP 711. The Indonesian Journal of Geography, 51, 147-154. https://doi.org/10.22146/ijg.39919

Dan Teknik, M. S. P. J., Nurdin, S., Mustapha, M. A., Lihan, T., \& Abd Ghaffar, M. A. Z. L. A. N. (2015). Determination of Potential Fishing Grounds of Rastrelliger kanagurta Using Satellite Remote Sensing and GIS Technique. Sains Malaysiana, 44, 225-232.

Lailia, N. L., Arafah, F., Jaelani, A., \& Pamungkas, A. D. (2015). Development of Water Quality Parameter Retrieval Algorithms for Estimating Total Suspended Solids and Chlorophyll-A Concentration Using Landsat-8 Imagery at Poteran Island Water. 2015 Joint International Geoinformation Conference, Kuala Lumpur, 28-30 October 2015, 55-62. https://doi.org/10.5194/isprsannals-II-2-W2-55-2015

Mustapha, A. M., Chan, Y. L., \& Lihan, T. (2010). Mapping of Potential Fishing Grounds of Rastrelliger kanagurta (Cuvier, 1871) Using Satellite Images. Map Asia 2010 \& ISG 2010, Kuala Lumpur, 26-28 July 2010, 1-9.

Nurdin, S., Lihan, T., \& Mustapha, A. M. (2012, March). Mapping of Potential Fishing Grounds of Rastrelliger kanagurta (Cuvier, 1816) in the Archipelagic Waters of Spermonde Indonesia Using Satellite Images. Proceedings of Malaysia Geospatial Forum, Kuala Lumpur, 6 March 2012, 1-9.

Nyamweya, C., Sturludottir, E., Tomasson, T., Fulton, E. A., Taabu-Munyaho, A., Njiru, M., \& Stefansson, G. (2016). Exploring Lake Victoria Ecosystem Functioning Using the Atlantis Modeling Framework. Environmental Modelling \& Software, 86, 158-167.

https://doi.org/10.1016/j.envsoft.2016.09.019 
Syariz, M. A., Jaelani, L. M., Subehi, L., Pamungkas, A., Koenhardono, E. S., \& Sulisetyono, A. (2015). Retrieval of Sea Surface Temperature over Poteran Island Water of Indonesia with Landsat 8 TIRS Image: A Preliminary Algorithm. The International Archives of Photogrammetry, Remote Sensing and Spatial Information Sciences, 40, 87. https://doi.org/10.5194/isprsarchives-XL-2-W4-87-2015

Tidd, A., Blanchard, J. L., Kell, L., \& Watson, R. A. (2018). Predicting Global Tuna Vulnerabilities with Spatial, Economic, Biological and Climatic Considerations. Scientific Reports, 8, Article No. 10572.

Trisakti, B., Sulma, S., \& Budhiman, S. (2004). Study of Sea Surface Temperature (SST) Using Landsat-7 ETM (In Comparison with Sea Surface Temperature of NOAA-12 AVHRR). Proceedings the 13th Workshop of OMISAR (WOM-13) on Validation and Application of Satellite Data for Marine Resources Conservation, Denpasar, Indonesia, 7-10.

Vayghan, A. H., Poorbagher, H., Shahraiyni, H. T., Fazli, H., \& Saravi, H. N. (2013). Suitability Indices and Habitat Suitability Index Model of Caspian kutum (Rutilus frisii kutum) in the Southern Caspian Sea. Aquatic Ecology, 47, 441-451. https://doi.org/10.1007/s10452-013-9457-9

Wanchana, W., \& Sayan, S. (2018). Application of GIS and Remote Sensing for Advancing Sustainable Fisheries Management in Southeast Asia. Fish for the People, 16, 21-28. 